\title{
LA HORA DEL DESASTRE: DESCOMPOSICIÓN SOCIAL E INDIGNACIÓN EN MÉXICO
}

Humberto Márquez Covarrubias

Unidad Académica en Estudios del Desarrollo, UAZ

hmarquez@estudiosdeldesarrollo.net

En las últimas tres décadas, el "modelo de desarrollo" en México ha sido muy exitoso: los ámbitos de valorización y sustracción de ganancias se acrecientan, en tanto que la élite concentra poder, riqueza y privilegios. El modelo se publicita como antesala de la prosperidad: las corporaciones son agentes del desarrollo y los despojados devienen personajes anacrónicos faltos de competitividad. La conflictividad social desencadenada por el despojo, explotación y discriminación pretende ser neutralizada mediante tácticas político-militares de persuasión, cooptación y coerción. Más que gobernabilidad, la impronta del modelo es la indignación y el miedo colectivo.

$\mathrm{E}$ stamos en el peor de los escenarios: el desmantelamiento de la soberanía y la profundización de la dependencia. Aunado al estancamiento económico y el desempleo estructural, el país ha desmantelado sus fundamentos económicos para someterse a los dictados del Consenso de Washington y la integración subordinada a Estados Unidos mediante instrumentos como el TLCAN y la Iniciativa Mérida. La relocalización corporativa en países como el nuestro, con sobreoferta laboral, laxitud legislativa ambiental y apoyos gubernamentales irrestrictos, propinan la puntilla a la soberanía laboral: la incapacidad de generar fuentes de empleo formal de calidad se depura con puestos laborales precarios e informales, y con la salida falsa al sicariato y la migración forzada. El desmantelamiento de la soberanía alimentaria representa la imposibilidad de garantizar la seguridad alimentaria y el quebrantamiento de la economía campesina, para favorecer a las agroindustrias transnacionales. El modelo consolida el poder del capital monopolista en detrimento de las capacidades productivas de la sociedad.

El eje de la estrategia de acumulación es socavar el salario, incluso por debajo de las necesidades mínimas para la reproducción social. En México, 5.8 millones de trabajadores, $12.7 \%$ de la PEA, padece condiciones críticas: perciben menos de dos salarios mínimos, trabajan más de 48 horas a la semana y carecen de seguridad social o prestaciones. En lugar de que la productividad y competitividad se basen en innovación, cadenas productivas o convergencia regional, emanan del abaratamiento laboral, la intensidad laboral y la prolongación de la jornada laboral. La explotación extrema del trabajo transfiere una parte sustancial del salario directo y el salario social a favor del capital corporativo.

La otra fuente de riqueza, la naturaleza, es arrasada como un simple insumo productivo que tiene que ser transformado a la mayor velocidad posible. La depredación es redoblada por el despojo de bienes comunes (tierra, agua, aire, bosques, biodiversidad) y bienes nacionales (empresas públicas, infraestructura, servicios públicos), bajo el ardid de que el sector social es improductivo y el sector público es ineficiente y corrupto. El intercambio desigual ambiental es patente: la capacidad de remplazo de la naturaleza no corresponde a la tasa de rendimiento empresarial y la capacidad de reproducción social se resquebraja. De un lado, las grandes corporaciones expanden sus fuentes de ganancia, con el apoyo del Estado, y, del otro, los sectores populares y las comunidades pierden autonomía y padecen el quebranto de sus modos de vida y trabajo. De manera enfática, las corporaciones extractivistas toman a México como enclave para sustraer, sin reparos éticos o ambientales, cantidades inconmensurables de materias primas (minerales, acuíferos, maderas, petróleo). La práctica indiscriminada de minaría a cielo abierto es un ejemplo perverso de la voracidad capitalista.

La pérdida de soberanía financiera obra a favor del capital financiero. Los grandes bancos de inversión, los bancos privados internacionales y los fondos de inversión, que recurren a la especulación para obtener altas ganancias en el corto plazo, controlan las operaciones bursátiles, bancarias y crediticias. El sistema financiero mexicano no existe como tal: la banca de desarrollo es prácticamente inexistente, la banca comercial está extranjerizada y los mercados de valores, dinero y divisas también son controlados por agentes especuladores externos. La banca del sector social y popular atraviesa por una crisis profunda que deteriora la capacidad productiva de las microempresas y productores rurales, en tanto que las prácticas crediticias son restrictivas y onerosas. En el colmo, los fondos de pensiones son canalizados a la especulación o financiamiento de grandes proyectos de 
inversión privados, en tanto que recursos presupuestales de todos los niveles de gobiernos se canalizan a operaciones bursátiles o esquemas de inversión público-privados. Las actividades ilícitas, como el lavado de dinero, articulan un conglomerado de actividades industriales, inmobiliarias, financieras, turísticas y comerciales vinculadas al crimen organizado, como el narcotráfico, el tráfico de armas y la extorsión. ${ }^{3} \mathrm{Y}$ los embates especulativos contra la moneda aunado a la recurrente fuga de capitales, la remisión de ganancias al extranjero y el oneroso pago por varios conceptos de deuda, representan una transferencia y fuga sistemática de excedente económico que vulnera la capacidad de acumulación nacional y abona a la expansión de las desigualdades sociales.

El Estado es intervenido por el sector corporativo y los poderes fácticos. Los gobernantes tutelan la gestación de nuevas fortunas y la consolidación de las existentes. Para las corporaciones, grupos de interés y poderes fácticos, el Estado representa un manjar en disputa al que se le puede arrancar parcelas de poder, dominios territoriales, apoyos institucionales y recursos presupuestales. Los principales beneficiarios son las grandes corporaciones, la alta burocracia, los jefes de la clase política y los cabecillas del crimen organizado, pero también los magnates de los grandes medios de comunicación y los jerarcas de la iglesia. Al intervenir al Estado, pretenden imponer sus visiones ideológicas y afianzar sus intereses económicos-políticos. Al desmantelar el Estado social, se impone el criterio de la nueva gerencia pública, es decir, el gobierno basado en preceptos gerenciales, por lo cual se estimula la privatización, la subcontratación, las concesiones, los proyectos de inversión público-privados y los programas de rescate empresarial. ${ }^{4}$

La destrucción del sistema de subsistencia social genera una desbordante sobrepoblación que, desde la óptica del capital, no tienen acomodo laboral. Los sujetos despojados tienen que buscar alternativas de subsistencia en la economía informal, la migración o la criminalidad. La exportación de fuerza de trabajo ha sido una de las especialidades de la economía nacional para depurar el excedente poblacional y abrir una fuente de divisas para sostener las cuentas externas y contener la conflictividad social. La superexplotación no se encajona en el Estado-nación, sino que se extiende en la economía del figurativo Sur global: los migrantes forzosos, que buscan trabajo allende las fronteras, habitualmente se insertan en ocupaciones precarizadas, segregadas e inseguras.

Como remache del modelo depredador, irrumpe la violencia armada que desgarra el tejido social e impone la percepción del miedo colectivo. El gobierno panista, que emerge de un cuestionado proceso electoral rayano en el fraude, ${ }^{5}$ emprende una "guerra contra el narcotráfico" que militariza la vida cotidiana y, subrepticiamente, coacciona a la población a fin de preservar el régimen político, que atraviesa la peor crisis de legitimidad de la historia reciente. Entre 2007 y 2011, el presupuesto para el aparato de seguridad se incrementó $75 \%$, pero la comisión de homicidios creció $65 \%$. El modelo policiaco-militar desencadena una espiral de violencia que contabiliza más de 70 mil muertos, 18 mil desaparecidos y 120 mil desplazados, amén de familias desgarradas, mujeres abandonadas, hijos desamparados y localidades amedrentadas. En ese contexto, los migrantes en tránsito procedentes de Centroamérica son presa fácil de asesinato, explotación, robo, secuestro, extorsión y violación. ${ }^{6}$ El tobogán de la violencia trastoca el tejido social y sega la vida de sectores, como las mujeres, sobreexpuestas como grupo vulnerable. Paradójicamente, la propagación del miedo genera un reclamo ciudadano de mano dura, de modo que el modelo policial asciende en una espiral esquizofrénica: la oferta genera su propia demanda.

La reproducción del sistema de poder depende de la dominación que se ejerce "desde arriba" y el consentimiento "desde abajo", salvo que las manifestaciones de inconformidad y rebelión logren cimbrar ese aparente equilibrio. La noción toral de democracia alude al "gobierno del pueblo", por tanto, para entender la configuración del régimen político es necesario aclarar si se manda sin obedecer y se obedece sin mandar o si se manda obedeciendo y se obedece mandando.

En México, no obstante la presunta "transición a la democracia", el primer escenario ha prevalecido. La alternancia electoral no ha cambiado, en esencia, el régimen político: perdura el régimen del mandato desobediente que el electorado convalida ritualmente en cada comicio. La democracia electoral propicia, simultáneamente, la depuración y reciclaje de la clase política, a condición de que se afiancen los pactos económico-políticos que soportan el modelo de acumulación. La "transición a la democracia" no es más que una democracia de élites operada por un sistema de partidos, la partidocracia, afecto al pragmatismo, el utilitarismo y el oportunismo. La ciudadanía es considerada como una amorfa masa de votantes que sólo puede expresarse votando: es una ciudadanía mínima.

Con la asunción del neoliberalismo, el pacto populista -que ofrecía una cierta red de protección al proletariado, campesinado y clase media- fue reemplazado por el neocorporativismo, la coalición de intereses del gran capital y el Estado, que emprendió una ofensiva contra los trabajadores y permitió la reinserción a los circuitos globales de capital mediante la premisa de que el país es un paraíso laboral. El corporativismo se entendía como el triunvirato del Estado, el capital y el trabajo. Un pacto multiclasista articulado por el presidencialismo priísta que regulaba el sistema político y las relaciones 
obrero-patronales, con ciertos márgenes de beneficio social y evidentes privilegios para los líderes. El noecorporativismo excreta al sector obrero para conceder todos los privilegios al sector empresarial. Los liderazgos corruptos mantienen bajo control a la masa obrera. Un ejemplo notable es el Sindicato Nacional de Trabajadores de la Educación (SNTE), que funge como una maquinaria electoral al servicio de los partidos dominantes. Los sindicatos blancos o de protección negocian los contratos laborales acordes a los intereses empresariales.

Ahora se divulga la idea de que la política, la pospolítica, ${ }^{7}$ no sirve para alentar luchas clasistas que pretenden transformar la sociedad, sino que es un campo reservado para los expertos, consultores, tecnócratas y administradores, que "saben como hacer las cosas", y a lo sumo los gobernantes "rinden cuentas" a la población. El ejercicio del poder termina por fetichizarse: ${ }^{8}$ los gobernantes exalta la imagen personal, toman decisiones sin consultar, emplean discrecionalmente los recursos públicos y prohíjan una camada de nuevos ricos. Ante la exigencia corporativa mantienen a raya la baratura del trabajo, contienen las movilizaciones sociales, criminalizar a los pobres, estigmatizan a los jóvenes y vilipendian a los críticos. Bajo el reduccionismo liberal, el Estado se constriñe a funciones de seguridad, vigilancia, ley y orden, y transfiere activos, recursos y servicios a la codiciosa órbita privada.

La ciudadanía, considerada un sujeto mínimo, es convocada a sufragar por personajes reciclados de la clase política que detentan el monopolio de la representación. La colonización de la conciencia colectiva es un logro inapreciable de los grandes medios de comunicación, destacadamente la televisión, que inoculan en sus audiencias ideas adocenadas de la política y anestesian el pensamiento con programación mediocre. El objetivo es despolitizar a la población, que permanece desinformada y renuncia a la potestad del mandato.

Tras un incesante bombardeo propagandístico, el sistema político pretende persuadir a la ciudadanía con la idea de que la expectativa del cambio sólo anida en las urnas. El adormecido debate político centellea fraseos demagógicos y consignas prefabricadas por ejércitos de asesores. El esmirriado menú presidencial oferta presuntos representantes populares que poco se atreven a anunciar la estrategia de desarrollo nacional. El PRI postula a un entusiasta promotor del neoliberalismo, Enrique Peña Nieto, respaldado abiertamente por los poderes fácticos y la tecnocracia liderada por el ex presidente Carlos Salinas. Es conspicuo el hecho de que su popularidad haya sido edificada por Televisa. ${ }^{9}$ No menos diferente, el PAN aboga por el continuismo neoliberal, también imbuido en la corrupción, ${ }^{10}$ y aderezado con el neoconservadurismo clerical y la mano dura del militarismo, en la endeble figura de Josefina Vázquez Mota. En dos sexenios, el PAN ha profundizado el modelo neoliberal y ejercido una suerte de cogobierno, que ha sido motejada como la emergencia de un partido gobernante de facto, el PRIAN, con el respaldo de partidos satelitales. La derecha neoliberal tiene un tercer candidato testimonial, Gabriel Quadri, que representa los intereses corruptos y oportunistas de la líder magisterial Elba Esther Gordillo. La coalición de centro-izquierda tiene su peor rostro en los partidos postulantes. El PRD padece una severa crisis de identidad: desde la izquierda asume prácticas de la derecha, y su dirigencia es una burocracia negociantes que hace de la cultura de la derrota un privilegiado modo de vida. Aparentemente, Andrés Manuel López Obrador no tiene partido político. La coalición lo respalda por un cálculo de oportunidad: como en la primera ocasión (2006), el candidato presidencial derrotado por estratagemas cibernéticos y prácticas fraudulentas, acarreó sin embargo un gran caudal de votos que permitió el feliz acomodo de politicastros neoliberales de izquierda en senadurías, diputaciones, gubernaturas, presidencias municipales y regidurías. El atractivo de este candidato es que ha propuesto un cambio en el modelo económico, aunque no lo ha definido con suma claridad. ${ }^{11}$

Comentaristas, intelectuales mediáticos y periodistas de los grandes medios de comunicación, encabezados por Televisa y TV Azteca, dan por sentado que vivimos en democracia, que es defendida, sin embargo, no con información verídica, sino con guerra sucia mediática. ${ }^{12}$ Empero, la noción de democracia se reduce a convalidar a la clase política gobernante, que viste distintos ropajes e insignias partidarias, pero que en los hechos resguarda con convicción el modelo neoliberal. Cuando los custodios del modelo advierten que el voto popular puede favorecer a candidatos moderados de izquierda, como Cuauhtémoc Cárdenas y Andrés Manuel López Obrador, desde las altas esferas del poder se orquesta el fraude electoral. En 1988, el sistema electoral se "cayó" para cometer un "fraude patriótico" y en 2006 se orquestó una colosal campaña negra que bajo la premisa de infundir miedo, anunciaba que el cambio era "un peligro para México" y más aún se cocinó un fraude "a la antigüita" y otro cibernético. ${ }^{13}$ Los mexicanos no estamos listos para la democracia, parecieran decir quienes mantienen a buen resguardo la coalición de intereses económico-políticos.

Los movimientos de rebeldía pretenden cambiar las estructuras de poder, pero siempre corren el riesgo de desactivarse ante la cooptación o coerción estatal. Algunas organizaciones dejan un legado social, como el Ejército Zapatista de Liberación Nacional (EZLN) que recupera la noción de democracia como "mandar obedeciendo", recrea el pensamiento crítico e implementa prácticas autogestivas. 
Los movimientos de resistencia responden a problemas inmediatos, no necesariamente orientados por un proyecto de cambio. Los movimientos rurales más representativos de la acumulación por despojo son del ámbito rural: El Barzón y el Campo no Aguanta Más. El embate contra los trabajadores ha propiciado la resistencia del Sindicato Mexicano de Electricistas y de los sindicatos de Mexicana de Aviación, mineros y el magisterio. La "guerra contra el narcotráfico" ha generado un gran caudal de víctimas y detonado la aparición del Movimiento por la Paz y con Justicia y Dignidad, que ha recorrido el país en una cruzada de concientización, pero también se ha sentado a negociar con el gobierno, sin grandes resultados.

En el ámbito cívico-electoral, el Movimiento de Regeneración Nacional (Morena), que sobrevivió al fraude electoral, sostiene la candidatura electoral de AMLO. Como una novedad, se suman los movimientos de vida efímera que sin programa, pero con indignación, responden a los llamados de las redes sociales tejidas en el ciberespacio. Básicamente se trata de campañas temáticas y coyunturales que avivan un cierto debate sobre temas como el voto nulo o la libertad de expresión, inclusive logran algunas movilizaciones públicas de amplia cobertura mediática (p. ej., \#YoSoy132). Debido a su naturaleza espontánea, cortoplacista y monotemática, los movimientos coyunturales no alcanzan una vida perdurable, aunque mueven fibras sensibles de sectores poblacionales que se mantenían un tanto apáticos y desinformados.

Los métodos de lucha de los movimientos de resistencia más socorridos, mítines y marchas, han sido asimilados y superados por el sistema de poder. La carencia de un proyecto de cambio para el largo plazo los condena a una vida efímera. Los procesos electorales han frustrado las aspiraciones de cambio, debido a que el modelo de democracia está reducido al ámbito electoral y la clase política está coaligada al modelo de acumulación vigente. El proyecto de cambio pasa por las urnas, pero va mucho más allá. Es una tarea que requiere la construcción de un poder social que, soportado por el conocimiento científico, la información y la participación, genere cambios en las estructuras de acumulación y poder para privilegiar los intereses sociales expresados en el bien común, la justicia, el desarrollo humano y la democracia.
Referencias

${ }^{1}$ Zepeda, Jorge (2007), Los amos de México, México, Planeta.

${ }^{2}$ Márquez, Humberto (2012), “Acumulación mundial centralizada”, Humberto Márquez, Roberto Soto y Edgar Záyago (coords.), El desarrollo perdido. Avatares del capitalismo en tiempos de crisis, México, Miguel Ángel Porrúa; James Petras (2012), "El capitalismo en la segunda década del siglo XXI: de la 'época dorada' a la edad oscura. Del capitalismo de oro al capitalismo oscuro", http://www.rebelion.org/noticia. php?id=148882.

${ }^{3}$ Reveles, José (2010), El cártel incómodo: El fin de los Beltrán Leyva y la hegemonía del Chapo Guzmán, México, Grijalbo Mondadori.

${ }^{4}$ Lizárraga, Daniel (2009), La corrupción azul. El despilfarro en la transiciones presidenciales, México, Debate.

${ }^{5}$ Díaz-Polanco, Héctor (2012), La cocina del diablo. El fraude de 2006 y los intelectuales, México, Temas de hoy.

${ }^{6}$ Casillas, Rodolfo (2011), "Usos identitarios y culturales en la transmigración por México”, Migración y desarrollo, vol. 9, no. 17.

${ }^{7}$ Zizek, Slavoj (2009), Sobre la violencia. Seis reflexiones marginales, Buenos Aires, Paidós.

${ }^{8}$ Dussel, Enrique (2006), 20 tesis de política. México, Siglo XXI.

${ }^{9}$ Villamil, Jenaro (2009), Si yo fuera presidente. El reality show de Peña Nieto, México, Grijalbo.

${ }^{10}$ Pérez, Ana Lilia (2010), Camisas azules, manos negras: el saqueo de Pemex desde Los Pinos, México, Grijalbo Mondadori.

${ }^{11}$ López, Andrés Manuel (2011), Nuevo proyecto de nación. Por el renacimiento de México, México, Grijalbo Mondadori.

${ }^{12}$ Villamil, Jenaro y Julio Scherer (2007), La guerra sucia de 2006. Los medios y los jueces, México, Grijalbo.

${ }^{13}$ Díaz-Polanco, Héctor, op. cit. 